RESEARCH PAPER

\title{
Understanding factors that influence smoking uptake
}

\author{
D B Buller, R Borland, W G Woodall, J R Hall, P Burris-Woodall, J H Voeks
}

Tobacco Control 2003;12(Suppl IV):iv16-iv25

\begin{abstract}
Objective: To explore relationships between patterns of smoking uptake and social context and attitudinal variables.

Design: Cross sectional survey.

Setting: Public schools in Tucson, Arizona and Albuquerque, New Mexico.

Participants: 982 children in grades 6-9 (ages 11-15 years).

Main outcome measures: Items measuring smoking history, nicotine dependence and quit attempts, susceptibility to smoking in the future, smoking norms, use of other tobacco products, attitudes toward smoking, and demographic characteristics.

Results: Overall, $43 \%$ of children had smoked a cigarette and $57 \%$ had never used them. Ever smokers lived in social contexts with more smoking and where smoking was normative. Among never users, 25\% are susceptible to smoking; these children have positive attitudes toward smoking, do not feel social pressure to stay off cigarettes, and had more friends who smoked. Among ever users, $36 \%$ were currently smoking in the past 30 days. Current users also lived in social context with more smoking and had positive attitudes toward smoking. Most users had tried to stop smoking. Only $9 \%$ of current users smoked daily; $29 \%$ had not smoked a whole cigarette. Greater cigarette consumption was associated with more favourable attitudes toward smoking. Most of past users were in early uptake: $95 \%$ had smoked less than 100 cigarettes but $49 \%$ were susceptible to smoking again.

Conclusions: There is promise in differentiating subgroups among the never, past and current use of cigarettes. Susceptibility within each of these groups was associated with similar patterns of attitudes and social context. These patterns in smoking uptake need to be confirmed prospectively.
\end{abstract}

$\mathrm{T}$ he issue of preventing young people from becoming smokers has traditionally focused on keeping them from trying their first cigarette. Conrad et al, in drawing attention to this narrow focus, argued for more research on factors determining progression. ${ }^{1}$ This need has also been highlighted by the emerging capacity to tailor prevention communication using computer technology. ${ }^{2-6}$ Indeed, this study is part of formative research to develop an internet based programme in which the audio based narration that accompanies on-line educational activities is tailored to make it maximally relevant to the individual student's experiences and expectations about smoking.

To tailor messages effectively requires an understanding of the audience's perspective on the material. In the case of smoking uptake, key factors include their experiences with and perceptions of cigarettes and smoking in their social context. Ideal tailoring would draw upon adolescent's known beliefs and experiences to relate scientific knowledge about smoking and its consequences in ways that are relevant to the adolescent. The survey reported here was performed to explore systematically some distinctions regarding young adolescents' experiences, perceptions, and social context related to smoking that could be useful for developing a programme to reduce future tobacco use. In the following paragraphs we describe several key variables that are related to smoking uptake and explore possible interactions between them, especially as it relates to the sort of interventions that might be relevant.

\section{THE SMOKING UPTAKE PROCESS}

\section{Ever use}

The most fundamental distinction in uptake is whether or not a person has ever used tobacco. The primary categories could be labelled as "never used" (or "never smoked") and "ever used" (smoked at any time). Ever users can be

subdivided into current users and past users, differentiated in terms of the US convention of having smoked in the past 30 days. We first consider issues around determinants of any tobacco use that can be used to further subdivide these categories.

Two key developments in understanding ever-use have been the work of Pierce and associates ${ }^{7}$ on susceptibility and attempts to adapt the stage based transtheoretical model (TTM) to uptake. ${ }^{8}$ Pierce et al found that anything other than a definite commitment not to smoke is associated with increased uptake. This implies that staying a non-smoker is an active process of resisting temptations to experiment. By contrast, thinking from TTM suggests three stages before experimentation: precontemplation, contemplation, and preparation to smoke. ${ }^{8}$ This implicates an active seeking out of opportunities to smoke, conceptually the reverse of Pierce et al's position.

Both processes could be operational in different settings or with different individuals. The Pierce et $a l^{7}$ algorithm places those who say they are "unlikely to smoke if offered" into the "susceptible" category, along with those saying they are "likely or certain to smoke". It may be important to differentiate those who do and do not see experimentation as likely. For example, a never user's agreement with the description that they are "unlikely" to smoke is viewed as a hedge on their possible behaviour. They need to be warned that their lack of commitment to not smoking puts them at risk if they come under pressure to try smoking, perhaps because they have not built counterarguments and other defences against offers to smoke. By contrast, someone saying they are likely to smoke is extremely vulnerable and it seems reasonable to assume that some of this vulnerability reflects curiosity. This interest in trying cigarettes needs to be challenged, so that they can develop a capacity to resist pressures to smoke before it is too late. 
Social context variables, such as smoking by peers or family members, are strongly related to smoking. ${ }^{9}$ Social context also may interact with susceptibility. A never user who believes they are likely to smoke in the next year and whose friends all smoke may be basing their belief on different factors from those who have no friends who smoke. In the former case, the person may feel as if they are currently resisting pressure, but doubt their capacity to maintain resistance given the availability of cigarettes in their social context. By contrast the susceptible never user without any smoking friends is more likely to admit susceptibility because of some intrinsic interest in trying it. If the context was right or the opportunity was there, they might be keen to try smoking; however, such a context or opportunity has not presented itself.

This suggests two dimensions for assessing never users, susceptibility, subdivided into at least three categories-not susceptible; susceptible (not certain not to); and vulnerable (see future smoking as probable)—and social context, based perhaps on the proportion of smokers in their friendship network.

\section{Past use}

Both susceptibility and social context are also relevant to past users, although susceptibility in this case relates to resumption of use. Again inferences of intention reasonably may differ as a function of social environment. For past users, two other factors are also important, the extent of past use and experiences of use. First, many people only ever have a puff or two or at most a couple of cigarettes while others experiment more intensively or smoke regularly before they stop. A distinction around total past consumption that can be appreciated is that those who have ever smoked more than 100 cigarettes are often considered to have been more than experimenters. Also, those who have past been daily smokers are also sometimes differentiated. As ex-dailies are rare among younger adolescents, we will not consider them further here, although that group should be analysed when focusing on adults' and older adolescents' smoking. Second, for some past users the experiences of use are positive and for others the experiences are either neutral or aversive. These experiences may affect the likelihood of future use.

\section{Current use}

The extent of use and the experiences of use are also relevant to current users. Extent of current use can be assessed by total consumption over any period and/or by the pattern of the consumption. For example, daily smokers are traditionally differentiated from non-dailies among adults. Daily smokers can be differentiated in terms of average consumption, but this solution is often practical only for adults. Among youth, most current users, including some quite high consumers, may not yet have established daily consumption patterns. That said, existence of daily smoking in young people implies a broader range of situations where they smoke than is likely for most non-dailies, although even nondailies may experience growing nicotine dependence in the smaller number of contexts in which they smoke. Whether divisions based on days smoked or total average consumption is best is an empirical issue.

Obviously, there are several factors that create an impetus for, or disinterest in, smoking uptake and understanding them is a longitudinal challenge. We do not claim that the few factors we consider are an exhaustive set. They are not. ${ }^{9}$ They merely are likely to be among the very influential factors, and are ones where it is relatively easy to collect information from young people and can be used to credibly tailor communication to reduce use based on that information. In this, we extend previous work by beginning to theorise about the importance of the distinctions we make from a health communication perspective. This led us to consider distinctions and interactions not previously considered important. Our specific aim in this paper is to explore relationships between the above contrasts and relevant social context and attitudinal variables using cross sectional data gathered in the baseline round of surveying for our internet based smoking prevention programme that tailors messages to young adolescents. ${ }^{2}{ }^{3}$ In particular, we aimed to determine which of the distinctions are likely to be most useful empirically in differentiating young adolescents in terms of tobacco use experiences and susceptibilities to make this health communication more precise, efficient, and effective.

\section{METHODS AND MATERIALS \\ Participants}

A sample of 982 adolescents in grades 6 (32\%), 7 (41\%), 8 (27\%) and 9 (1\%) (ages 11-15 years) completed the survey (44\% male, 56\% female). Students were recruited from 12 middle and junior high schools in Tucson, Arizona and Albuquerque, New Mexico in the 1998-99 school year (17133 completed surveys per school). Parents provided active informed consent and children assented in writing to complete the survey. Participation exceeded $75 \%$ across the schools. Within the sample, $65 \%$ reported being of Hispanic origin (24\% non-Hispanic white) and $79 \%$ that their first language was English $(21 \%$ spoke Spanish as their first language). Half of the children (54\%) reported living with both parents and a quarter $(26 \%)$, with only their mothers. School performance varied: $51 \%$ received mostly A's, $13 \%$, mostly B's, $25 \%$, mostly B's and C's, and $11 \%$, mostly C's or lower; $50 \%$ had not been absent from school but $15 \%$ had been absent for more than one week.

\section{Measures}

The questionnaire contained 177 items but each child completed slightly fewer items as there was branching based on responses about smoking history.

\section{Smoking history}

Children were asked whether they had ever smoked a cigarette, even a puff. Those who had were asked if they had smoked 100 cigarettes in their lifetime, smoked in the past 30 days, ever smoked a whole cigarette, and smoked every day. Questions also assessed age at first cigarette; whether child or friends think of child as a smoker; number of cigarettes smoked per day; whether they liked the last few cigarettes; if cigarettes hurt their eyes, nose, mouth, throat, lungs; and how much they inhaled cigarette smoke. Children were asked if they had ever bought cigarettes, how they obtained most cigarettes, and if they usually had their own pack of cigarettes. Two items inquired whether their parents knew they smoked and about how upset parents would be if they knew the child smoked.

\section{Nicotine dependence}

Indicators of nicotine dependence included how soon after waking up do they smoke and whether they smoke more in first two hours after awaking than during rest of day from the Fagerstrom tolerance questionnaire. ${ }^{10}$ Items in this questionnaire were recently validated against a saliva cotinine measure with adolescent smokers. ${ }^{11}$ Children reported whether they find it hard to keep from smoking when their friends are smoking; how much time they spent trying to find cigarettes; and if they ever delay or put off doing something to smoke. 


\section{Quit attempts}

Questions on quitting included whether the child had gone without a cigarette for 24 hours; attempts to quit smoking; and reactions when trying to quit (cravings, nervousness, eating more, trouble concentrating, feeling irritated).

\section{Questions for non-smokers and past puffers}

Children who had not smoked, or smoked in the past but had not smoked a whole cigarette, or said they had stopped reported on their susceptibility to smoking in the future. ${ }^{7}$

\section{Smoking norms}

All children reported on how many of their closest friends smoke and normative perceptions of smoking by students in their grade and by adults. They described smoking rules in their home for visitors and family members and influences to not smoke cigarettes by reference persons including mother, best friend, and people their own age.

Use of other tobacco products

Children described whether they ever used smokeless tobacco or cigars.

\section{Attitudes toward smoking cigarettes}

Thirty (30) Likert-type (strongly agree/strongly disagree) items assessed children's attitudes toward smoking. In factor analysis, a first factor, labelled "positive mental aspects of smoking", included beliefs that smoking helps people relax, reduce stress, feel more comfortable with other people, keep their weight down, forget their worries, cheer up when in a bad mood, and feel more self confident (high scores reflected more positive beliefs; $\alpha$ reliability $=0.89$ ). A second factor, "positive appearance of smoking", comprised: smoking is enjoyable; makes people look more grown up; tastes good; makes people look tough; makes people look sexy; and helps people look beautiful (higher scores showed more favourable opinions; $\alpha=0.88)$. "Negative physical/social effects of smoking" included: smoking makes it hard for people to play sports and do other physical activities; I strongly dislike being around people who are smoking; smoking makes you more likely to get heart disease; smoking is as addictive as other drugs such as heroin or cocaine; I would never date people who smoke; inhaling someone else's cigarette smoke can cause lung cancer in smokers; and seeing someone smoking turns me off (higher scores indicated more negative beliefs; $\alpha=0.80$ ). The items in the fourth factor-smoking is something everyone should try at least once; smoking is something you need to try before deciding to do it or not; there is no harm in having a cigarette once in a while; smoking low tar and low nicotine cigarettes is less harmful to your health than smoking regular cigarettes; I spend a lot of time each day thinking about smoking; smokeless tobacco is not addictive; and smokeless tobacco does not cause cancerwere "rationalisations about the safety of smoking" (higher scores showed more rationalisations; $\alpha=0.77$ ).

\section{Demographic characteristics}

A final group of questions assessed demographic characteristics (grade; race; Hispanic ethnicity; date of birth converted to age; place of birth; language use; presence of parents in the home) and school performance (plan to finish high school; educational plans beyond high school; grades received in school; days absent in last four weeks).

\section{Survey procedures}

Informed parental consent forms were distributed by research staff to parents either at the first orientation session at school or by sending them home with students. Questionnaires were administered in school by research assistants and project investigators in group situations with children separated to maintain privacy. The questionnaire began with a printed assent form, on which children indicated whether they volunteered to be surveyed. Children completed the survey in approximately 45 minutes. Research assistants checked the questionnaires for completeness and responses were entered into computer databases and checked for accuracy by data management staff.

\section{Statistical analysis}

Data quality was monitored throughout the data collection and entry procedures. Data entry was checked through a random audit of forms and found to not exceed $1 \%$. The analysis was performed using SAS. It involved calculating basic frequencies and means on all variables. Differences between categories of cigarette use were assessed using $\chi^{2}$ and analysis of variance.

\section{RESULTS}

\section{Major usage categories}

The first task was to classify children based on their smoking history. Of the 953 children who responded to the item, 43\% reported that they had smoked a cigarette, even a puff, leaving $57 \%$ of the sample as never smokers ( 29 children did not answer this question and were dropped from the analysis). Among ever smokers, $36 \%$ had smoked a cigarette in the past 30 days ( $15 \%$ of all respondents) and were classified as current smokers. The remaining 64\% $(28 \%$ overall) were classified as past smokers.

\section{Ever users versus never users}

Comparison of ever and never users of cigarettes is provided in table 1. Compared to never users, ever users perceived that more students had tried smoking and smoked at least once a week and had more friends who smoked. They also were more susceptible to offers of cigarettes from friends and reported that they found it harder to not smoke when they were someplace where their friends were smoking. Compared to never users, ever smokers also believed that referent persons (for example, mothers, friends) felt it was not as important that they stay off cigarettes. Smoking was permitted in more areas of ever users' homes than never users' homes. Ever smokers expressed more positive attitudes toward the mental effects, appearance features, and safety of smoking and were less concerned about the negative physical and social consequences than never users. Compared to never users, a greater proportion of ever users also used cigars and smokeless tobacco.

\section{Current versus past users}

In relation to past users, current users were more likely to perceive that smoking was normative among their peers, have more smoking friends, have their friends see them as smokers, and consider smoking as more permissible in their homes (table 2). Current users believed that it was less important to mothers and peers that they stay off smoking than past users. Current users are more uncertain of their status as smokers than past users, although a sizable proportion of both groups do not know how to classify their smoking pattern. It is notable that $10 \%$ of current users described themselves as ex-smokers, suggesting that they may see themselves as having quit.

Overall, current users hold more positive attitudes toward the mental effects, appearance features, and safety of smoking than past users. They also believe that smoking helps them meet others. Current users are less concerned about the negative physical and social effects of smoking than past users. 
Table 1 Factors associated with ever smoking cigarettes

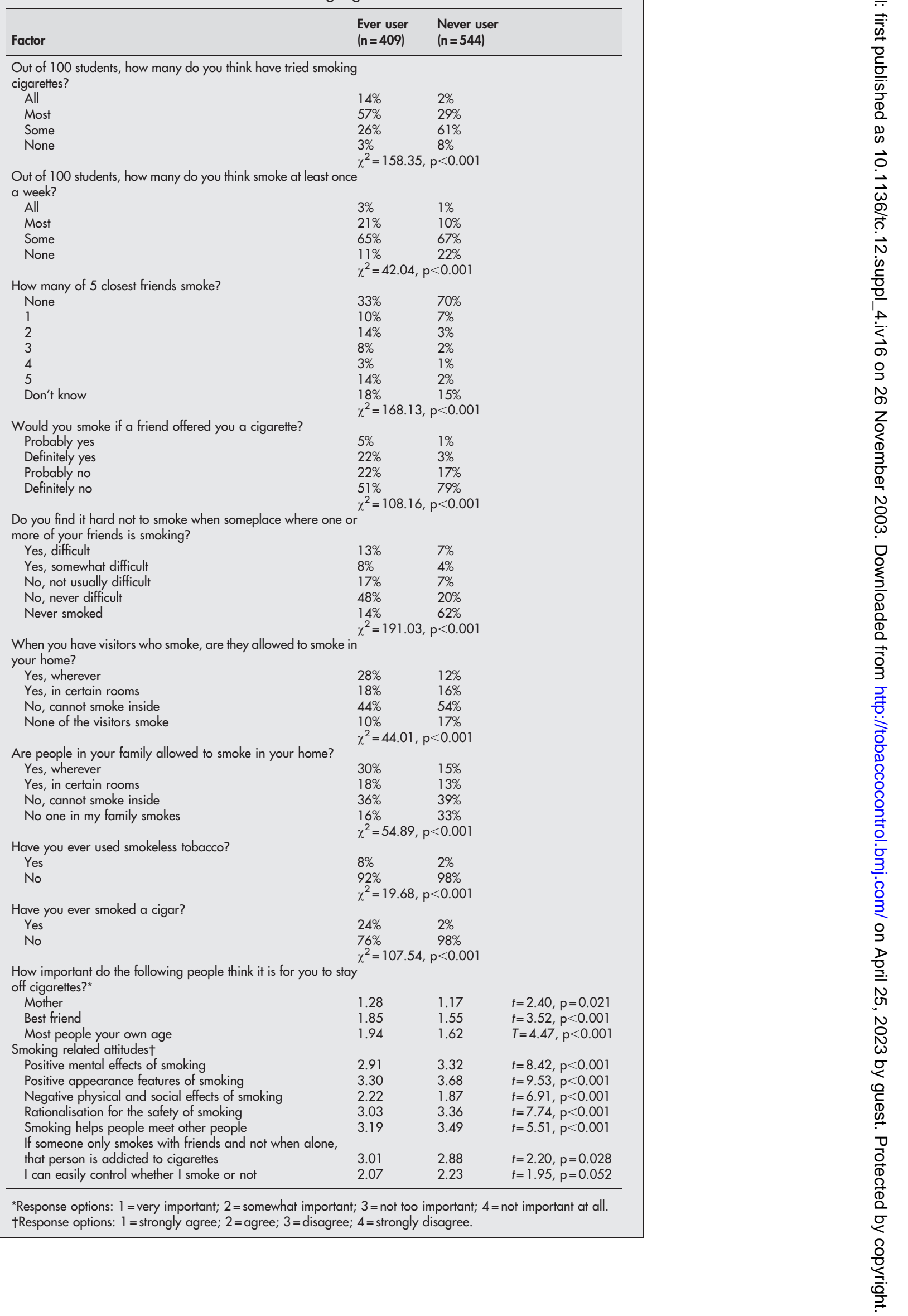


Table 2 Factors associated with current versus past use of cigarettes

\begin{tabular}{|c|c|c|c|}
\hline Factor & $\begin{array}{l}\text { Current user } \\
(n=146)\end{array}$ & $\begin{array}{l}\text { Past user } \\
(n=256)\end{array}$ & \\
\hline \multicolumn{4}{|l|}{$\begin{array}{l}\text { Out of } 100 \text { students, how many do you think smoke } \\
\text { at least once a week? }\end{array}$} \\
\hline All & $7 \%$ & $1 \%$ & \\
\hline Most & $29 \%$ & $16 \%$ & \\
\hline Some & $56 \%$ & $70 \%$ & \\
\hline None & \multicolumn{2}{|c|}{$\chi^{2}=17.91, p<0.001$} & \\
\hline \multicolumn{4}{|l|}{ How many of 5 closest friends smoke? } \\
\hline None & $15 \%$ & $43 \%$ & \\
\hline 1 & $6 \%$ & $12 \%$ & \\
\hline 2 & $17 \%$ & $13 \%$ & \\
\hline 3 & $13 \%$ & $6 \%$ & \\
\hline 4 & $6 \%$ & $1 \%$ & \\
\hline 5 & $28 \%$ & $6 \%$ & \\
\hline Don't know & $15 \%$ & $19 \%$ & \\
\hline & $\chi^{2}=67.00, p$ & .001 & \\
\hline \multicolumn{4}{|l|}{ How do you think of yourself? } \\
\hline A smoker & $19 \%$ & $1 \%$ & \\
\hline A non-smoker & $20 \%$ & $60 \%$ & \\
\hline An ex-smoker & $10 \%$ & $10 \%$ & \\
\hline Not sure & $51 \%$ & $29 \%$ & \\
\hline & $\chi^{2}=77.98, p$ & .001 & \\
\hline \multicolumn{4}{|l|}{ How do your friends think of you? } \\
\hline A smoker & $17 \%$ & $3 \%$ & \\
\hline A non-smoker & $31 \%$ & $59 \%$ & \\
\hline An ex-smoker & $8 \%$ & $5 \%$ & \\
\hline \multirow{2}{*}{ Not sure } & $44 \%$ & $33 \%$ & \\
\hline & $\chi^{2}=44.04, p$ & .001 & \\
\hline \multicolumn{4}{|l|}{ How did you try to quit smoking? } \\
\hline Never tried & $34 \%$ & $17 \%$ & \\
\hline Just drifted away & $11 \%$ & $10 \%$ & \\
\hline Stopped, no problem & $36 \%$ & $59 \%$ & \\
\hline Stopped with cravings & $12 \%$ & $5 \%$ & \\
\hline \multirow[t]{2}{*}{ Cut down, then quit } & $7 \%$ & $9 \%$ & \\
\hline & $\chi^{2}=16.43, p$ & .002 & \\
\hline \multirow{2}{*}{\multicolumn{4}{|c|}{$\begin{array}{l}\text { How much did you crave a cigarette last time } \\
\text { went without cigarettes? }\end{array}$}} \\
\hline & & & \\
\hline Not at all & $45 \%$ & $74 \%$ & \\
\hline A little & $18 \%$ & $10 \%$ & \\
\hline Some & $14 \%$ & $6 \%$ & \\
\hline A lot & $10 \%$ & $5 \%$ & \\
\hline Never tried & $13 \%$ & $4 \%$ & \\
\hline & $\chi^{2}=19.72, p$ & .001 & \\
\hline When you have visitors who smoke, are they allowed & & & \\
\hline $\begin{array}{l}\text { smoke in your home? } \\
\text { Yes, wherever }\end{array}$ & $43 \%$ & $20 \%$ & \\
\hline $\begin{array}{l}\text { Tes, wherever } \\
\text { Yes, in certain rooms }\end{array}$ & 19 & 17 & \\
\hline No, cannot smoke inside & 33 & 51 & \\
\hline None of the visitors smoke & & 12 & \\
\hline & $\chi^{2}=26.30, p$ & .001 & \\
\hline Are people in your family allowed to smoke in your & & & \\
\hline home? & & & \\
\hline Yes, wherever & $45 \%$ & $22 \%$ & \\
\hline Yes, in certain rooms & $19 \%$ & $17 \%$ & \\
\hline No, cannot smoke inside & $26 \%$ & $42 \%$ & \\
\hline No one in my family smokes & $10 \%$ & $19 \%$ & \\
\hline & $\chi^{2}=25.52, p$ & .001 & \\
\hline Have you ever used smokeless tobacco? & & & \\
\hline Yes & $12 \%$ & $5 \%$ & \\
\hline No & $88 \%$ & $95 \%$ & \\
\hline & $\chi^{2}=4.46, p<$ & & \\
\hline Have you ever smoked a cigar? & & & \\
\hline Yes & $34 \%$ & $18 \%$ & \\
\hline No & $66 \%$ & $82 \%$ & \\
\hline & $\chi^{2}=11.33, p$ & .001 & \\
\hline $\begin{array}{l}\text { How important do the following people think it is for } \\
\text { you to stay off cigareftes?* }\end{array}$ & & & \\
\hline Mother & 1.42 & 1.21 & $t=2.32, p=0.021$ \\
\hline Best friend & 2.46 & 1.80 & $t=3.84, p<0.001$ \\
\hline Most people your own age & 2.20 & 1.83 & $t=3.15, p=0.002$ \\
\hline Smoking related attitudes $\dagger$ & & & \\
\hline Positive mental effects of smoking & 2.68 & 3.03 & $t=4.20, \mathrm{p}<0.001$ \\
\hline Positive appearance features of smoking & 3.07 & 3.42 & $t=4.74, p<0.001$ \\
\hline Negative physical and social effects of smoking & 2.39 & 2.13 & $t=3.08, p=0.002$ \\
\hline Rationalisations for the safety of smoking & 2.82 & 3.15 & $t=4.76, p<0.001$ \\
\hline $\begin{array}{l}\text { Smoking helps people meet other people } \\
\text { If someone only smokes with friends and not when }\end{array}$ & 2.94 & 3.32 & $t=4.00, p<0.001$ \\
\hline alone, that person is addicted to cigarettes & 2.97 & 3.03 & $t=0.55, p=0.585$ \\
\hline I can easily control whether I smoke or not & 2.11 & 2.03 & $t=0.60, p=0.547$ \\
\hline
\end{tabular}

*Response options: 1 = very important; 2 =somewhat important; 3 =not too important; $4=$ not important at all. †Response options: 1 = strongly agree; 2 =agree; 3 =disagree; $4=$ strongly disagree. 
Most users have tried to stop smoking. However, the number who tried to quit is lower among current users, who also report more cravings when they stopped smoking than past users.

\section{Exploration of subgroups within each major category Never users}

Never users were classified based on susceptibility to smoking in the next year. Among all never users, 6\% were vulnerable (replied that they definitely or probably would smoke in next year); 19\% were susceptible (probably would not); and $75 \%$ were not susceptible (definitely would not) to smoking in the future. Perhaps not surprisingly, susceptibility categories, based on likely use of cigarettes in the next year, was related to another question used by Pierce et al, ${ }^{7}$ likelihood of accepting a cigarette from a friend: not susceptible-probably/definitely yes ( $1 \%)$, probably/definitely no $(99 \%)$; susceptible-probably/definitely yes $(4 \%)$, probably/definitely no (96\%); vulnerable-probably/definitely yes (43\%), probably/definitely no (57\%) (Fisher's exact test $\mathrm{p}<0.001)$.

As can be seen from table 3, with increasing susceptibility, never users reported more favourable attitudes toward smoking and less anxiety about the negative physical and social affects of smoking. They also were less likely to believe that peers felt it was important that they stay off cigarettes with increasing susceptibility. Indeed the opinions of the vulnerable group are very similar to those of current users on the measures that apply to both (table 2).

We related susceptibility to friends smoking (none, versus all other categories). More vulnerable never users had at least one friend who smoked $(61 \%)$ than susceptible never users (34\%) and not susceptible never users $(26 \%$, Fisher's exact test $\mathrm{p}<001)$. To further test the idea that this combination of susceptibility and smoking by friends influences attitudes toward smoking differentially, 3 (susceptibility) $\times 2$ (no friends smoke $v$ at least one friend smokes) analysis of variance was performed on the attitudinal measures. We found an interaction for the perceived importance peers felt about keeping off smoking, but not for the other attitudinal measures. Vulnerable never users (no friends smoke $M=2.00$; at least one friend smokes $M=2.41$ ) and susceptible never users $(\mathrm{M}=1.49, \mathrm{M}=2.10$, respectively) felt that it was less important to most people their own age if they stayed off cigarettes when they had friends who smoke, but the number of friends smoking did not affect this perception among never users who were not susceptible to smoking in the future $(M=1.56, M=1.58$, respectively) $(\mathrm{F}=3.50, \mathrm{p}=0.031)$. It is notable that among those without friends who smoke, only the vulnerable group had elevated perceptions of the acceptability of smoking to their peers.

\section{Past smokers}

Past smokers (smoked a cigarette in the past but not in the last month) were subdivided into three categories on level of past use: $5 \%$ were past regular smokers who had smoked at least 100 cigarettes in the past and had smoked a whole cigarette; $37 \%$ were past experimenters who had not smoked 100 cigarettes in the past but had smoked a whole cigarette; and 58\% were past puffers who had not smoked 100 cigarettes in the past or a whole cigarette. Among past users, $19 \%$ were vulnerable (definitely or probably would smoke in the future), $30 \%$ were susceptible (probably would not), and $51 \%$ were not susceptible (definitely would not) to smoking again. Responses did not vary as a function of level of past smoking.

Vulnerable past users were least likely to believe that their peers felt they should stay off cigarettes (table 3 ). They also held the most positive attitudes toward the mental effects, appearance features, and safety of smoking (table 3). Indeed, as for the never users, their attitudes were very similar to current users. This raises the question as to why they had not smoked recently. This might relate to social context, so we related susceptibility to friends smoking. Vulnerable past users were more likely to have friends who smoked (72\%)

Table 3 Differences due to susceptibility in factors associated with uptake of smoking among never users and past users

\begin{tabular}{|c|c|c|c|c|c|c|}
\hline & \multicolumn{3}{|l|}{ Never users } & \multicolumn{3}{|l|}{ Past users } \\
\hline & $\begin{array}{l}\text { Not susceptible } \\
(\mathrm{n}=404)\end{array}$ & $\begin{array}{l}\text { Susceptible } \\
(n=103)\end{array}$ & $\begin{array}{l}\text { Vulnerable } \\
(n=31)\end{array}$ & $\begin{array}{l}\text { Not susceptible } \\
(n=116)\end{array}$ & $\begin{array}{l}\text { Susceptible } \\
\text { (n=69) }\end{array}$ & $\begin{array}{l}\text { Vulnerable } \\
(\mathrm{n}=44)\end{array}$ \\
\hline \multicolumn{7}{|c|}{$\begin{array}{l}\text { How important do the following people think it } \\
\text { is for you to stay off cigarettes?* }\end{array}$} \\
\hline Mother & $\begin{array}{l}1.14 \\
F=2.65, p=0.072\end{array}$ & 1.25 & 1.34 & $\begin{array}{l}1.18 \\
F=1.25, p=0.288\end{array}$ & 1.19 & 1.19 \\
\hline Best friend & $\begin{array}{l}1.47 \\
F=5.10, p=0.007\end{array}$ & 1.64 & 2.11 & $\begin{array}{l}1.58 \\
F=4.26, p=0.016\end{array}$ & 1.46 & 2.03 \\
\hline Most people your own age & $\begin{array}{l}1.56 \\
F=7.98, p<0.001\end{array}$ & 1.72 & 2.26 & $\begin{array}{l}1.69 \\
F=2.88, p=0.059\end{array}$ & 1.90 & 2.10 \\
\hline \multicolumn{7}{|l|}{ Smoking related attitudes } \\
\hline Positive mental effects of smoking & $\begin{array}{l}3.44 \\
F=29.21, p<0.001\end{array}$ & 3.06 & 2.65 & $\begin{array}{l}3.17 \\
F=5.53, p=0.005\end{array}$ & 2.98 & 2.77 \\
\hline Positive appearance features of smoking & $\begin{array}{l}3.77 \\
F=33.56, p<0.001\end{array}$ & 3.50 & 3.12 & $\begin{array}{l}3.57 \\
F=7.87, p<0.001\end{array}$ & 3.38 & 3.16 \\
\hline $\begin{array}{l}\text { Negative physical and social effects of } \\
\text { smoking }\end{array}$ & $\begin{array}{l}1.76 \\
F=16.78, p<0.001\end{array}$ & 2.15 & 2.21 & $\begin{array}{l}2.09 \\
F=0.74, p=0.479\end{array}$ & 2.10 & 2.26 \\
\hline Rationalisations for the safety of smoking & $\begin{array}{l}3.45 \\
F=23.68, p<0.001\end{array}$ & 3.17 & 2.86 & $\begin{array}{l}3.30 \\
F=8.43, p<0.001\end{array}$ & 3.08 & 2.90 \\
\hline Smoking helps people meet other people & $\begin{array}{l}3.57 \\
F=13.96, p<0.001\end{array}$ & 3.37 & 2.89 & $\begin{array}{l}3.40 \\
F=1.64, p=0.196\end{array}$ & 3.32 & 3.14 \\
\hline $\begin{array}{l}\text { If someone only smokes with friends and } \\
\text { not when alone, that person is addicted } \\
\text { to cigarettes }\end{array}$ & $\begin{array}{l}2.88 \\
F=0.24, p=0.787\end{array}$ & 2.86 & 3.00 & $\begin{array}{l}2.96 \\
F=0.70, p=0.500\end{array}$ & 3.10 & 3.07 \\
\hline $\begin{array}{l}\text { I can easily control whether I smoke } \\
\text { or not }\end{array}$ & $\begin{array}{l}2.21 \\
F=0.42, p=657\end{array}$ & 2.34 & 2.21 & $\begin{array}{l}2.09 \\
F=1.25, p=0.288\end{array}$ & 1.85 & 2.19 \\
\hline
\end{tabular}

*Response options: 1 = very important; $2=$ somewhat important; $3=$ not too important; $4=$ not important at all.

†Response options: 1 = strongly agree; 2 =agree; 3 =disagree; $4=$ strongly disagree. 
Table 4 Differences in factors associated with uptake among current users

\begin{tabular}{|c|c|c|c|c|c|}
\hline \multirow[b]{2}{*}{ Factor } & \multicolumn{4}{|c|}{ Cigarette consumption } & \multirow[b]{2}{*}{$\begin{array}{l}\text { Daily } \\
(n=13)\end{array}$} \\
\hline & $\begin{array}{l}\text { Low } \\
(n=47)\end{array}$ & $\begin{array}{l}\text { Moderate/high } \\
(n=56)\end{array}$ & $\begin{array}{l}\text { Puffer } \\
(n=42)\end{array}$ & $\begin{array}{l}\text { Non-daily } \\
(n=88)\end{array}$ & \\
\hline \multicolumn{6}{|l|}{ Reaction to last few cigareftes } \\
\hline Liked & $21 \%$ & $60 \%$ & $15 \%$ & $38 \%$ & $75 \%$ \\
\hline Neither & $44 \%$ & $23 \%$ & $22 \%$ & $36 \%$ & $8 \%$ \\
\hline Disliked & & $17 \%$ & $63 \%$ & $26 \%$ & $17 \%$ \\
\hline & FET $p<0.001$ & & FET $p<0.001$ & & \\
\hline \multicolumn{6}{|c|}{ Do you have own pack of cigarettes? } \\
\hline Yes & $5 \%$ & $51 \%$ & - & $16 \%$ & $85 \%$ \\
\hline No & & $49 \%$ & - & $84 \%$ & $15 \%$ \\
\hline & FET $p<0.001$ & & FET $p<0.001$ & & \\
\hline \multicolumn{6}{|c|}{$\begin{array}{l}\text { How much did you inhale smoke deeply into } \\
\text { your lungs }\end{array}$} \\
\hline Not at all & $3 \%$ & $13 \%$ & - & $8 \%$ & $8 \%$ \\
\hline A little & $27 \%$ & $18 \%$ & - & $29 \%$ & $8 \%$ \\
\hline Some & $54 \%$ & $29 \%$ & - & $41 \%$ & $23 \%$ \\
\hline A lot & $16 \%$ & $40 \%$ & - & $22 \%$ & $61 \%$ \\
\hline & FET $p=0.013$ & & FET $p=0.036$ & & \\
\hline \multicolumn{6}{|c|}{$\begin{array}{l}\text { How long after waking up do you usually } \\
\text { smoke your first cigarette? }\end{array}$} \\
\hline$<30$ mins & $0 \%$ & $21 \%$ & - & $0 \%$ & $54 \%$ \\
\hline$>30$ mins & $4 \%$ & $18 \%$ & - & $11 \%$ & $8 \%$ \\
\hline In affernoons & $38 \%$ & $35 \%$ & - & $37 \%$ & $15 \%$ \\
\hline In evening & $58 \%$ & $26 \%$ & - & $52 \%$ & $23 \%$ \\
\hline & FET $p=0.011$ & & FET $p<0.001$ & & \\
\hline \multicolumn{6}{|c|}{$\begin{array}{l}\text { Did you ever delay or put off something so you } \\
\text { could smoke? }\end{array}$} \\
\hline Yes & $4 \%$ & $22 \%$ & - & $10 \%$ & $38 \%$ \\
\hline No & $96 \%$ & $78 \%$ & - & $90 \%$ & $62 \%$ \\
\hline & FET $p=0.067$ & & FET $p=0.019$ & & \\
\hline \multicolumn{6}{|c|}{$\begin{array}{l}\text { Out of } 100 \text { students, how many do you think } \\
\text { smoke at least once a week? }\end{array}$} \\
\hline All/most & $33 \%$ & $52 \%$ & $18 \%$ & $41 \%$ & $58 \%$ \\
\hline Some/none & $67 \%$ & $48 \%$ & $82 \%$ & $58 \%$ & $42 \%$ \\
\hline & FET $p=0.090$ & & FET $p=0.009$ & & \\
\hline \multicolumn{6}{|l|}{ How do you think of yourself? } \\
\hline A smoker & $7 \%$ & $40 \%$ & $7 \%$ & $17 \%$ & $62 \%$ \\
\hline A non-smoker & $20 \%$ & $4 \%$ & $41 \%$ & $15 \%$ & $0 \%$ \\
\hline An ex-smoker & $9 \%$ & $13 \%$ & $2 \%$ & $12 \%$ & $23 \%$ \\
\hline Not sure & $64 \%$ & $43 \%$ & $50 \%$ & $56 \%$ & 155 \\
\hline & FET $p<0.001$ & & FET $p<0.001$ & & \\
\hline \multicolumn{6}{|c|}{ How do your friends think of you? } \\
\hline A smoker & $7 \%$ & $30 \%$ & $12 \%$ & $16 \%$ & $39 \%$ \\
\hline A non-smoker & $30 \%$ & $17 \%$ & $44 \%$ & $28 \%$ & $15 \%$ \\
\hline An ex-smoker & $9 \%$ & $11 \%$ & $2 \%$ & $9 \%$ & $8 \%$ \\
\hline Not sure & $54 \%$ & $42 \%$ & $42 \%$ & $47 \%$ & $38 \%$ \\
\hline & FET $p=0.021$ & & FET $p=0.166$ & & \\
\hline How did you try to quit smoki & & & & & \\
\hline Never tried & $38 \%$ & $38 \%$ & - & $31 \%$ & $59 \%$ \\
\hline Just drifted away & $21 \%$ & $2 \%$ & - & $13 \%$ & $0 \%$ \\
\hline Stopped, no problem & $32 \%$ & $29 \%$ & - & $39 \%$ & $8 \% \%$ \\
\hline Stopped, had cravings & $6 \%$ & $20 \%$ & - & $9 \%$ & $33 \%$ \\
\hline Cut down, then quit & $3 \%$ & $11 \%$ & - & $8 \%$ & $0 \%$ \\
\hline & FET $p=0.027$ & & FET $p=0.014$ & & \\
\hline $\begin{array}{l}\text { How much did you crave a cic } \\
\text { went without cigarettes? }\end{array}$ & & & & & \\
\hline Not at all & $40 \%$ & $41 \%$ & - & $51 \%$ & $8 \%$ \\
\hline A little & $26 \%$ & $15 \%$ & - & $18 \%$ & $15 \%$ \\
\hline Some & $11 \%$ & $15 \%$ & - & $13 \%$ & $23 \%$ \\
\hline A lot & $9 \%$ & $11 \%$ & - & $9 \%$ & $15 \%$ \\
\hline Never tried & $14 \%$ & $18 \%$ & - & $9 \%$ & $39 \%$ \\
\hline & FET $p=0.854$ & & FET $p=0.003$ & & \\
\hline Have you ever used smokeless & & & & & \\
\hline Yes & $5 \%$ & $21 \%$ & $11 \%$ & $9 \%$ & $36 \%$ \\
\hline No & $95 \%$ & $79 \%$ & $89 \%$ & $91 \%$ & $64 \%$ \\
\hline & FET $p=0.023$ & & FET $p=0.047$ & & \\
\hline Have you ever smoked a ciga & & & & & \\
\hline Yes & $35 \%$ & $48 \%$ & $16 \%$ & $39 \%$ & $67 \%$ \\
\hline No & 65 & 52 & 84 & 61 & 33 \\
\hline & FET $p=0.280$ & & FET $p=0.003$ & & \\
\hline How important do the followin & & & & & \\
\hline $\begin{array}{l}\text { it is tor you to stay oft cigarett } \\
\text { Mother }\end{array}$ & $\begin{array}{l}1.28 \\
t=234 \mathrm{p}=0.022\end{array}$ & 1.80 & $\begin{array}{l}1.25 \\
F=8.18,0<0.001\end{array}$ & 1.37 & 2.50 \\
\hline Best friend & $\begin{array}{l}f=2.34, p=0.024 \\
2.24\end{array}$ & 2.10 & $\begin{array}{l}r=8.18, p<0.001 \\
2.23\end{array}$ & 2.13 & 3.00 \\
\hline & $t=0.49, \mathrm{p}=0.625$ & & $F=2.31, p=0.105$ & & \\
\hline Most people your own age & 2.26 & 2.42 & 2.15 & 2.11 & 3.20 \\
\hline
\end{tabular}


Table 4 Continued

\begin{tabular}{|c|c|c|c|c|c|}
\hline \multirow[b]{2}{*}{ Factor } & \multicolumn{4}{|c|}{ Cigarette consumption } & \multirow[b]{2}{*}{$\begin{array}{l}\text { Daily } \\
(n=13)\end{array}$} \\
\hline & $\begin{array}{l}\text { Low } \\
(n=47)\end{array}$ & $\begin{array}{l}\text { Moderate/high } \\
(n=56)\end{array}$ & $\begin{array}{l}\text { Puffer } \\
(n=42)\end{array}$ & $\begin{array}{l}\text { Non-daily } \\
\text { ( } n=88)\end{array}$ & \\
\hline \multicolumn{6}{|l|}{ Smoking related attitudes $\dagger$} \\
\hline Positive mental effects of smoking & $\begin{array}{l}2.74 \\
F=2.14, p=0.148\end{array}$ & 2.48 & $\begin{array}{l}2.73 \\
F=7.35, p=0.001\end{array}$ & 2.79 & 1.93 \\
\hline Positive appearance features of smoking & $\begin{array}{l}3.13 \\
F=1.21, p=0.274\end{array}$ & 2.97 & $\begin{array}{l}3.09 \\
F=5.18, p=0.007\end{array}$ & 3.17 & 2.51 \\
\hline Negative physical and social effects of smoking & $\begin{array}{l}2.36 \\
F=0.71, p=0.401\end{array}$ & 2.50 & $\begin{array}{l}2.23 \\
F=1.45, p=0.240\end{array}$ & 2.43 & 2.58 \\
\hline Rationalisations for the safety of smoking & $\begin{array}{l}2.92 \\
F=3.25, p=0.075\end{array}$ & 2.64 & $\begin{array}{l}2.90 \\
F=5.49, p=0.005\end{array}$ & 2.88 & 2.23 \\
\hline Smoking helps people meet other people & $\begin{array}{l}2.87 \\
F=0.18, p=0.672\end{array}$ & 2.96 & $\begin{array}{l}2.80 \\
F=3.42, p=0.036\end{array}$ & 3.08 & 2.42 \\
\hline $\begin{array}{l}\text { If someone only smokes with friends and not } \\
\text { when alone, that person is addicted to cigarettes }\end{array}$ & $\begin{array}{l}2.88 \\
\mathrm{~F}=0.09, \mathrm{p}=0.771\end{array}$ & 2.94 & $\begin{array}{l}2.97 \\
F=1.13, p=0.327\end{array}$ & 3.04 & 2.58 \\
\hline I can easily control whether I smoke or not & $\begin{array}{l}1.88 \\
F=0.84, p=0.361\end{array}$ & 2.08 & $\begin{array}{l}2.42 \\
F=1.89, p=0.156\end{array}$ & 1.99 & 2.00 \\
\hline
\end{tabular}

than susceptible past users $(65 \%)$ and not susceptible past users (44\%, Fisher's exact test $\mathrm{p}=0.001)$. Thus, opportunity may contribute to perceived vulnerability to resume smoking.

Finally, among past users, we compared the susceptibility categories on whether past users enjoyed their last few cigarettes. Most past users who were not susceptible to smoking in the future reported that they disliked $(83 \%)$ or neither liked nor disliked the last few cigarettes (15\%; liked $=2 \%$ ). This was less so for susceptible past users (disliked $=64 \%$, neither liked nor disliked $=32 \%$, liked $=4 \%$, and even less so for vulnerable past users (disliked $=48 \%$, neither $=34 \%$, liked $=18 \%$; Fisher's exact test $\mathrm{p}<0.001$ ).

\section{Extent of current use}

Only $9 \%$ of current smokers smoked cigarettes daily (smoking all 30 days in the past 30 days; $4 \%$ of all respondents); $62 \%$ had smoked a whole cigarette, but smoked less than daily; and 29\% had not smoked a whole cigarette and were classified as puffers. Consumption was low; excluding puffers, $45 \%$ of current smokers reported smoking less than 1 cigarette per day on average (low consumption), 45\% $1-5$ cigarettes per day (moderate), and $10 \%$ more than 5 cigarettes per day (high). We combined the latter two groups for analysis purposes. Most current smokers in this age range appear to be experimenters and puffers, early in their trajectory of uptake, and thus probably amenable to preventive interventions.

The extent of cigarette use by current users was associated with several factors (see table 4 for comparisons). Compared to daily users, non-daily smokers and puffers had less favourable experiences with their last few cigarettes and many did not smoke again immediately after their first cigarette. Non-daily smokers did not inhale the smoke as deeply into their lungs, mostly smoked in the afternoon and evening (as opposed to within 30 minutes of awakening), rarely delayed or put off other activities to smoke or had their own pack of cigarettes, and often stopped smoking without any difficulty and with few cravings. Fewer non-daily smokers and puffers see themselves as smokers and are less likely to report also using cigars and smokeless tobacco. Nondaily users and puffers also hold less favourable attitudes toward the mental effects, appearance features, and safety of smoking and believe that their mother and most people their age feel it is important for them to stay off cigarettes (table 3).
Similar patterns emerged when measuring extent of use by the average number of cigarettes smoked per day (table 4). Besides the factors already mentioned, children who smoked less than one cigarette per day rarely smoked daily and few believed that their friends considered them to be smokers.

\section{DISCUSSION}

The results of this study showed that there is considerable promise in differentiating subgroups among the three main categories of tobacco use (never, past, and current use). As expected the three main categories can be discriminated over a wide range of attitudinal and other variables. What is less well known is that there exists within each group readily distinguishable subgroups whose pattern of attitudes and reported social environment relates more closely to one of the other main groups. These results have application to the design of interventions to reduce the uptake of smoking by children.

The extension of Pierce et $\mathrm{al}^{\prime} \mathrm{s}^{7}$ susceptibility measure into three categories seems to be useful. Further, the current study clearly shows that this is an important variable for past users as well as for never users. The more susceptible groups among past and never users have attitudes more positive to smoking and more friends who smoke. Susceptibility may be an endogenous variable that potentially mediates many other beliefs and as such is a core construct to measure and to target for intervention, either directly or indirectly through some of its likely determinants. Given the combination of increased opportunity and less negative attitudes, it is not clear exactly what is inhibiting tobacco use in the more vulnerable never users, but one cannot be assured that this circumstance will persist for long in the face of obvious social pressures to smoke. Interventions should pay special attention to the vulnerable and susceptible subgroups to reduce their favourable outlook on smoking and arm them with strategies to resist social pressure.

There are clearly two types of triers among past users. One group-low susceptible past users (and perhaps some number of other past smokers)-has tried smoking and appears to be committed to not doing it again. They exist in social environments that may be protective against smoking and hold beliefs that are consistent with not smoking. From an intervention point of view, these smokers may simply need to be reinforced to maintain committed to not smoking again. The other group-susceptible and vulnerable past users (and probably some other past smokers) - appear to be very early in the uptake trajectory. A number of these past users do not seem to have made a clear decision on smoking 
and are not sure whether they are smokers or non-smokers. They also hold relatively positive attitudes toward smoking and have fewer concerns about the harms of smoking. More report enjoying the last few cigarettes they smoked, but almost half did not. They also have more friends who smoke. It seems important to focus intervention efforts on this latter group and use strategies that combat the positive reactions to smoking, perhaps by stressing unpleasant early experiences with smoking and providing skills to resist social pressures to smoke, with the aim of getting susceptible and vulnerable past and never users to commit to not smoking again.

Among current users both the pattern and consumption variables have similar associations with third variables. Which measure is best is unclear on the basis of our data. The different measures of extent of use each have merit, but some combination of these variables may be most useful. There may be two types of non-daily users, that can be differentiated on level of consumption, and when examining older adolescents, there will be a need to differentiate daily users in terms of consumption as well. This leaves a potential group of high consumption non-dailies who may smoke more than low consumption dailies, making the scale non-ordinal. This would be important if pattern or use was of importance, but we have insufficient data in this study to explore these possibilities. An alternative is to use consumption as the measure (that is, number of cigarettes smoked per day), but if this were to be the solution, it may be preferable to use it as a continuous variable, suitably transformed to account for its expected non-normality.

The puffers are a curious group, at least among current users. Their experiences of smoking are more negative, and they see smoking as less prevalent among their peers, yet their attitudes toward smoking are very similar to the nondaily users. We suspect that this group is in a transitory period of uptake with a variety of possible trajectories: no future use or the many trajectories of use. It may be useful to try to subdivide puffers into those who may never smoke again and those who are actively trying it out and may progress toward more regular smoking. There are many who may already be ex-smokers in this former group and can be combined with those who only ever smoked a few cigarettes in the past and are classified as "triers", leaving the term "experimenter" for those who play around with smoking for a more extensive period. These findings are consistent with Flay et al' $^{12}$ view that it is important to distinguish early from more advanced experimentation; however, it is not yet clear where the best place to split the notional continuum of use to allow this distinction.

The analyses confirmed much previous research that uptake of smoking is predicted by features of children's social environments that support smoking. . Such support can be real (for example, more friends smoking, visitors and family members permitted to smoke in the home) or perceived (for example, normative beliefs that more students smoke, beliefs that staying off cigarettes is less important to mother and peers).

The findings say less about the role of experience of use, because experience needs to be considered in the context of patterns of past use and perhaps even current use. Unfortunately, we did not have sufficient cases to explore this issue fully. However, it is clear that low level users report predominantly negative experiences. Smoking is an inherently noxious habit which smokers need to learn to tolerate. Focusing on these noxious aspects in prevention interventions may be a very important strategy for preventing progress from early experimentation to regular use.

There are some other variables that may warrant further investigation as key factors. Learning to inhale cigarette smoke, having a pack of cigarettes, and delaying or putting off doing something in order to smoke appear to be markers of uptake and therefore important to intervention efforts. It may be that smokers need to inhale before they get the proper psychoactive effects, so it could be an important way station on the road to dependence. Likewise, having a pack of cigarettes may make it easier to smoke and promote higher consumption leading to more dependence. These variables could be highlighted to early smokers as indicators of growing dependence on cigarettes to increase their perceived vulnerability to addiction and creating motivation to stop smoking to avoid becoming dependent.

These patterns of uptake, when further confirmed, may carry implications for what smoking prevention strategies might be successful for different groups of adolescents. In our present project, they support our tailored messages that attempt to reduce vulnerable never users' desire to try smoking and to alert them to the inherent social pressures that arise from friends who smoke. The patterns also reinforce our decision to tailor the messages in our internet based programme to (a) teach past users how to let friends know that they do not want to smoke again, and (b) highlight that smoking is not enjoyable.

There are some obvious implications for interventions: never users need to be encouraged to maintain that status; however, those who are vulnerable will not be convinced by reference to their anti-smoking attitudes, because their attitudes are pro-smoking. Extra work will be required to challenge their more positive views of smoking. The results also suggest that there may be commonalities as well as differences between stopping past users from resuming and preventing never users from trying cigarettes. The susceptibility index may work similarly in both groups of children, but there are obvious differences in past users' decisions about smoking because they have recourse to their experience with cigarettes, experiential information not available to never users. We are using these and other strategies in our intervention and will be in a position to discuss the relative utility of strategies in more detail when we can support our arguments with data from that study.

In addition to our strategies for intervention, future research should explore whether low susceptible past users remain committed non-smokers and, therefore, may not need additional intervention to avoid future smoking. However, it is clear that the susceptible and vulnerable past users do require help if they are not to resume use. If the factors associated with susceptible and vulnerable past users prospectively predict which past users will have positive initial reactions to smoking and progress toward more frequent smoking, these groups should become a prime candidate for prevention interventions. Prevention efforts that seek to correct this group's normative beliefs about the prevalence of smoking, increase the perceived social and biological harms of smoking, and elevate perceived social support for non-smoking may be effective. Similar concerns over preventing relapse by past users have arisen in other areas of addictions and prevention research. Relapse to substance use is best thought of as comprising a range of outcomes rather than as a binary outcome. ${ }^{13}$ Studies have indicated that positive coping behaviours are strong predictors of not relapsing after cessation of alcohol drinking in adults. ${ }^{14} 15$ Thus, it may be that messages that emphasise and bolster positive coping behaviours are most effective in maintaining non-smoking status for both past users and never users. Adolescent substance abuse prevention researchers have also devised booster sessions that follow on the implementation of prevention curricula as a way to maintain non-use. ${ }^{16}$ Overall then, a continued focus on maintaining non-smoking status across uptake and vulnerability dimensions is warranted. 


\section{What this paper adds}

Prevention of smoking has focused more on keeping young people from trying their first cigarette and less on arresting progression from initial tries to regular smoking. Susceptibility to smoking and social context variables like the proportion of smokers in friendship networks affects whether children try cigarettes. These factors also may influence progression to regular smoking, although this process may be influenced by extent of past use and experiences of use.

The results of this survey confirmed that susceptibility to smoking remains a predictor of future smoking for children who have already tried smoking but had not smoked recently, although there may be a group of children who have tried smoking and are committed to not doing it again. Smoking by others in the social environment also remains an important influence on smoking progression. Extent and pattern of consumption varies within current smokers with high consumption periodic smokers and low consumption daily smokers being seen. Children who have not smoked a whole cigarette (that is, puffers) appear to be in a transitory period of uptake. Although they can report negative experiences with smoking, they generally have favourable attitudes toward it. Tailored prevention communication should continue to focus on children who are susceptible to smoking and those with smokers in their social environments, even after they try their first cigarette. Once the first cigarette is tried, communication also needs to address patterns and experiences of smoking, experiential information not available to never smokers.

Finally, this paper has not addressed what needs to be done to intervene with current users to convince them to stop smoking. Any analysis of this issue needs to be informed by the recent work of DiFranza and others. ${ }^{17}$

We make no claims for the variables we have explored being exhaustive. In addition to the dynamic factors we have investigated, consideration needs to be given to whether these factors might vary by gender (for example, Koval et $\left.a l^{18}\right)$, age or socioeconomic circumstances. With computer tailoring capacity, all of these variables can be taken into account where the evidence suggests that different forms of intervention are required, or even just to make the material seem more relevant provided production resources are available. This study has also avoided consideration of broader issues, such as personality dimensions, other problem behaviours, and psychopathology. While all have been linked to smoking (for example, Lewinsohn et al ${ }^{19}$ ), they may be far too complex to be used as the basis for framing simple communications. Where relevant, they need to be the focus of detailed and individualised approaches at levels of intervention complexity beyond anything we currently envision.

The results of this study should be treated as preliminary. Prospective studies are required to see if these distinguishing features of the three main groups have predictive value for the outcome of smoking uptake and whether attempts to intervene using them can arrest smoking uptake. It is clear that susceptibility to smoking is an important cognitive variable both for smokers and former smokers. Among ever users extent of use is clearly important, as may be other factors which have not been extensively studied here. It is only when we begin to think about the meaning that variables have for people and how we might talk to them about these factors that we can begin to design studies where the predictor variables can be intervened on in ways that parallel the presumed routes of influence. We believe that this is the approach that prevention research needs to take into the future. To advance this agenda, we need to be exploring potential predictors of smoking progression or regression in longitudinal analyses, which we intend to do with the follow up data from the trial evaluating the internet based programme.

\section{ACKNOWLEDGEMENT}

This project was funded by a grant from the National Cancer Institute (CA78206).

\section{Authors' affiliations}

D B Buller, J H Voeks, The Cooper Institute, Denver, Colorado, USA

R Borland, The Cancer Council Victoria, Carlton South, Victoria,

Australia

W G Woodall, P Burris-Woodall, University of New Mexico,

Albuquerque, New Mexico, USA

J R Hall, University of Arizona, Tucson, Arizona, USA

\section{REFERENCES}

1 Conrad K, Flay B, Hill D. Why children start smoking cigarettes: predictors of onset. BrJ Addict 1992;87:1711-24.

2 Buller DB, Woodall WG, Hall JR, et al. A web-based smoking cessation and prevention program for children ages 12 to 15. In: Rice R, Atkin C, eds. Public communication campaigns, 3rd ed. Thousand Oaks, California: Sage, 2001:357-72.

3 Hall JR, $A \times B$, Brown $M$, et al. Challenges to producing and implementing the web-based smoking prevention and cessation program. Electronic J Communication 2001:11.

4 Kreuter MW, Strecher VJ, Glassman B. One size does not fit all: the case for tailoring print materials. Annals Behav Med 1999;21:276-83.

5 Prochaska JO, DiClemente CC, Velicer WF, et al. Standardized, individualized, interactive and personalized self-help programs for smoking cessation. Health Psychol 1993;12:399-405.

6 Strecher VJ, Kreuter M, Den Boer DJ, et al. Effects of computer-tailored smoking cessation messages in family practice settings. J Family Pract 1994;39:262-70.

7 Pierce JP, Choi WS, Gilpin EA, et al. Validation of susceptibility as a predictor of which adolescents take up smoking in the United States. Health Psychol 1996:15:355-61.

8 Pallonen UE, Prochaska JO, Velicer WF, et al. Stages of acquisition and cessation for adolescent smoking: an empirical integration. Addict Behav 1998;23:303-24

9 US Department of Health and Human Services. Preventing tobacco use among young people. A report of the Surgeon General, 1994. Atlanta, Georgia: Public Health Service, Centers for Disease Control and Prevention, Office on Smoking and Health, 1994. (US Government Printing Office Publication No S/N 017-001-00491-0).

10 Radzius A, Moolchan ET, Henningfield JE, et al. A factor analysis of the Fagerstrom tolerance questionnaire. Addict Behav 2001;26:303-10.

11 Prokorov AV, Moor CD, Pallonen UE, et al. Validation of the modified fagerstrom tolerance questionnaire with salivary cotinine among adolescents. Addict Behav 2000;25:429-33.

12 Flay B, Hu F, Richardson J. Psychosocial predictors of different stages of cigarette smoking among high school students. Prev Med 1998;27:9-18.

13 Westerberg VS, Miller WR, Harris RJ, et al. The topography of relapse in clinical samples. Addict Behav 1998;23:325-337.

14 Miller WR, Westerberg VS, Harris RJ, et al. What predicts relapse? Prospective testing of antecedent models. Addiction 1996;91(suppl): 155-72.

15 Connors GJ, Maisto SA, Zywiak WH. Understanding relapse in the broader context of post-treatment function. Addiction 1996;91(suppl): 173-90.

16 Botvin GJ, Dusenbury L. Substance abuse prevention and the promotion of competence. In: Bond LA, Compas BE, eds. Primary prevention and promotion in the schools. Newbury Park, California: Sage Publications, 1989.

17 Difranza J, Savageau JA, Fletcher K, et al. Measuring the loss of autonomy over nicotine use in adolescents: the DANDY (development and assessment of nicotine dependence in youths) study. Arch Pediatr Adolesc Med 2002; 156:397-403.

18 Koval JJ, Pedersen LL, Mills CA, et al. Models of the relationship of stress, depression and other psychosocial factors to smoking behavior: a comparison of a cohort of students in grades 6 and 8. Prev Med 2000;30:463-77.

19 Lewinsohn P, Brown R, Seeley J, et al. Psychosocial correlates of cigarette smoking abstinence, experimentation, persistence and frequency during adolescence. Nicotine Tobacco Res 2000;2:121-31. 